\title{
"Só isso que é meu ideia": fórmulas de fechamento como uma particularidade discursivo-interacional do Português Kaxinawá
}

\author{
"Só isso que é meu ideia": closing formulas as a \\ discourse-interactional particularity of Cashinaua Portuguese
}

Beatriz Christino $^{1}$

Orcid: 0000-0001-6997-6499

João Pedro Peres da Costa ${ }^{2}$

Orcid: 0000-0002-1481-2558

DOI: $10.26512 /$ rbla.v12i1.30039

Recebido em março/2020 e aceito em abril/2020

Resumo

Nos limites deste artigo, analisamos uma provável particularidade da etiqueta interacional dos Kaxinawá (povo da família etnolinguística Pano, que habita 12 Terras Indígenas no Acre) em interações transculturais, ou seja, aquelas envolvendo a participação de nãoindígenas. Dessa maneira, nosso objeto de estudo consiste em construções que denominamos de fórmulas de fechamento, bastante similares a estruturas formulaicas recorrentes em narrativas em Kaxinawá e (ao que nossas observações vêm indicando) sem paralelo no Português (L1) do Alto Juruá. Descrevemos a sua configuração estrutural, assim como a sua função no desenvolvimento da interação. Contendo os operadores "isso" e/ou "assim", essas fórmulas de fechamento funcionam, no Português Kaxinawá, como sinalizadoras do encerramento de tópicos (ou subtópicos) discursivos e de turnos de fala.

Palavras-chave: Povo Kaxinawá. Português Kaxinawá. Etiqueta Interacional. Marcadores discursivo-interacionais. Português Indígena.

\begin{abstract}
Within the limits of this paper, we analyze a likely unique feature of the Cashinahuas' (belonging to the Panoan ethnolinguistic family and living in 12 Indigenous Reserves in Acre) interactional etiquette in transcultural interactions, i. e. those involving the participation of non-Indigenous people. Thus, our research subject consists of constructions we named
\end{abstract}

1 Linguista, Professora Adjunta IV do Departamento de Letras Vernáculas (Setor de Língua Portuguesa) da Faculdade de Letras da Universidade Federal do Rio de Janeiro (UFRJ). E-mail: bchristino@ufrj.br.

2 Graduando em Licenciatura em Letras: Português-Espanhol pela Universidade Federal do Rio de Janeiro (UFRJ), bolsista PIBIC-UFRJ. E-mail: joao.pedro.peres.iperes@gmail.com. 
formulaic closing forms, which are very similar to recurrent formulaic structures found in narratives in Cashinahua language and (as our observations have been noticing) without parallel in Upper Juruá River Portuguese (L1). We describe its structural configuration in addition to its function within the interactional dynamics. Including the discursive markers "isso" and/or "assim", these formulaic closing forms signalize the end of discourse topics (or subtopics), as well as the end of turns.

Keywords: Cashinahua People. Cashinahua Portuguese. Interactional Etiquette. Discourseinteractional markers. Indigenous Portuguese.

\section{Introdução}

As especificidades das variedades indígenas de Português Brasileiro não se limitam às esferas da fonologia, morfologia, morfossintaxe e sintaxe, marcando presença também em outras dimensões, como a pragmática e o discurso. Nesse sentido, seus traços particulares podem ser reconhecidos, inclusive, no âmbito da etiqueta interacional (v. Maher 1994).

Nos limites deste artigo, analisamos o que consideramos ser uma particularidade da etiqueta interacional dos Kaxinawá reconhecível em interações transculturais, aquelas em que sua variedade própria de Português viabiliza a comunicação com os não-indígenas. Sendo assim, nos debruçamos sobre estruturas formulaicas que funcionam como sinalizadores do encerramento de tópicos discursivos e de turnos de fala. Por essa razão, nomeamos tais estruturas como 'fórmulas de fechamento'.

Para contextualizar o emprego desse processo discursivo-interacional, começamos, na segunda seção, com uma breve caracterização da variedade de Português dos Kaxinawá. Na seção seguinte, explicitamos os referenciais teórico-metodológicos que nortearam nossa análise. A quarta seção, dedicada ao exame aprofundado das fórmulas de fechamento, leva em conta a sua função no desenvolvimento da interação e, paralelamente, a sua configuração estrutural.

\section{Os Kaxinawá e sua Variedade Específica de Português}

Os Kaxinawá ou Huni Kuin, da família etnolinguística pano, vivem na região que veio a se configurar como fronteira entre o Brasil e o Peru, na Amazônia Ocidental. O termo Huni Kuin corresponde à autodenominação empregada pelos Kaxinawá (assim como por outros povos Pano) e tem como tradução aproximada a expressão "humanos autênticos". Por sua vez, o termo Kaxinawá, cuja tradução aproximada vincula-se a "gente do morcego", vem a ser a forma pejorativa como esse grupo foi denominado por outros povos Pano da região (para maiores informações sobre a origem dos termos Kaxinawá e Huni Kuin, v. Lagrou (1991, 12-13)). Vale apontar, ainda, que Huni Kuin representa um conceito consideravelmente complexo e que esse termo não se limita a nomear a etnia também conhecida por Kaxinawá. Nesse sentido, conforme aponta Camargo $(2013,45)$ : 
Kuin, termo intraduzível, tem seu significado moldado segundo seu referente contextual. Um caxinauá, como outros grupos panos, por variações fonéticas, autodenominam-se huni kuin, 'homem kuin.' Um caxinauá pode ser visto como um huni kuinmaki, ou seja, um 'homem não kuin' se o enunciador caxinawá descartar outro caxinauá de seu espaço referencial. Uma pessoa campa [ashaninka], da família arauaque, torna-se um kuin se estiver dentro do espaço conceitual kuin do enunciador caxinauá. O sintagma adjetival huni kuin, ou seja, caxinauá, pode tornar-se complemento de betsa, "outro", e designar um huni kuin que não seja um caxinauá: Huni kuin betsa, como no enunciado kanpadan huni kuin betsa 'O campa é outro huni kuin'. (Camargo 2013, 45)

Do lado brasileiro da fronteira, os Kaxinawá vivem em um conjunto de doze Terras Indígenas (doravante, também, TI) situadas no estado do Acre, mais especificamente nos municípios de Feijó, Jordão, Manoel Urbano, Marechal Thaumaturgo, Santa Rosa do Purus e Tarauacá. Em oito delas, os Kaxinawá são a única etnia presente, enquanto que nas Terras Indígenas Alto Rio Purus e Kulina do (Rio) Envira, eles convivem com a etnia Kulina (Pano); na TI Katukina/Kaxinawá (no Rio Envira) com os Katukina (Pano) e na TI Kaxinawá Ashaninka do Rio Breu com os Ashaninka (Aruaque). ${ }^{3}$

O contato entre a sociedade não-indígena e os Kaxinawá, em solo brasileiro, se deu a partir do final do século XIX, tendo sido a brutalidade do invasor destacada por historiadores Kaxinawá (Maná Kaxinawá et al. 2002), assim como por não-indígenas (Iglesias 2008). Nessa época, seringalistas promoviam expedições que eram verdadeiras caçadas às populações indígenas no Acre, as chamadas "correrias", com o objetivo não só de dominar e anexar seus territórios, mas também de utilizar sua mão de obra escravizada nos seringais. Por conta disso, o período de 1890 até 1920 foi batizado de "tempo das correrias".

Em função da acentuada queda do preço da borracha no mercado internacional, os seringalistas não mais puderam contar com a mão de obra de migrantes do Nordeste (Weinstein 1993), e passaram a intensificar a violenta exploração da força de trabalho de indígenas escravizados, o que marcou o "tempo do cativeiro" (da década de 1920 até 1980). Os Kaxinawá foram proibidos, então, de usar sua língua e obrigados, sob pena de sofrerem castigos corporais, mutilações ou, até mesmo, a morte, a falar a língua portuguesa. Essa terrível situação somente começa, realmente, a se alterar em meados dos anos 1980, momento em que a intensa luta do movimento indígena leva à conquista do chamado "tempo dos direitos".

3 Dados retirados do site <http://www.funai.gov.br/index.php/indios-no-brasil/terrasindigenas> selecionada a UF Acre, em seguida clicando em "pesquisar". 
Hoje totalizando, segundo o Sistema de Informação da Atenção à Saúde Indígena, mais de 10 mil pessoas, os Kaxinawá configuram a etnia indígena de maior população no Acre. Do lado brasileiro da fronteira, são, em sua maioria, bilíngues em Kaxinawá ${ }^{4}$ e sua variedade específica de Português, utilizada não só na comunicação com não-indígenas, mas também com falantes de outras línguas ameríndias, como os Ashaninka, com quem, como apontado acima, dividem a TI Kaxinawá-Ashaninka do Rio Breu.

Da mesma forma que as demais variedades de Português Indígena, o Português Kaxinawá representa um significativo índice de identidade étnica, conforme ressaltam os trabalhos de Maher (1996; 1998), acerca da pragmática do que ela denominou "Português Índio", e o Referencial Curricular Nacional para as Escolas Indígenas. Neste último, pode-se ler:

Os povos indígenas têm, cada um deles, o seu modo próprio de falar a língua portuguesa. Esses modos de falar o português têm, quase sempre, marcas muito específicas da língua de origem do povo em questão: no vocabulário, na gramática, na pronúncia. Esses modos de expressão devem ser respeitados na escola e fora dela, já que também são atestados de identidade indígena (MEC/ Secretaria de Educação Fundamental 1998, 114, ênfase adicionada).

Diversos estudos vêm revelando essas "marcas muito específicas" de variedades de Português Indígena. Amado (2015), por exemplo, delineou particularidades fonológicas (como a neutralização do traço de vozeamento nas consoantes oclusivas e a apócope das sílabas átonas finais), morfossintáticas (caso da marcação da flexão de plural nas últimas posições do sintagma nominal e da não distinção para o tempo passado no sistema de flexão verbal), e discursivas (como o uso de marcadores para iniciar e finalizar tópicos discursivos) do Português Timbira. Trabalhando com um povo que se vincula, também, ao grupo dos Timbira, os Parkatejê, Ferreira (2005) verificou que as palavras portuguesas que continham uma consoante oclusiva desvozeada eram pronunciadas com a sua homorgânica sonora pelos Parkatejê.

Com base em dados coletados em agosto e setembro de 1969, uma equipe de pesquisadores coordenada por Rosa Virgínia Mattos e Silva pôde reconhecer traços característicos do Português Kamayurá, como a presença de uma variação livre entre as consoantes surdas e sonoras e a realização das vogais médias tônicas exclusivamente com timbre aberto (v. Mattos e Silva 1988). Investigando o Português dos Fulniô, Costa (1993) percebeu que a ordem dos componentes do sintagma nominal poderia assumir configurações específicas, a exemplo de "medo muito" (Costa 1993, 159). Christino e Lima e Silva (2012), por sua vez, notaram que a escrita em Português de professores Kaingang em

4 Os Kaxinawá se referem à sua língua como hantxa kuin. 
formação encerrava sujeitos de número singular associados à flexão verbal com morfemas de plural, em uma combinação que, possivelmente, espelharia a distinção Kaingang entre ação única (ou seja, um único evento) e ação múltipla (mais de um evento). Sendo assim, um dado como "A língua podem mudar em vários sentidos" indicaria a realidade de que são vários os processos de mudança por que passa uma língua (ação múltipla).

No ano de 2012, nosso grupo de pesquisa iniciou um exame da morfossintaxe do Português Kaxinawá, apoiado em registros de áudio gentilmente cedidos pela Comissão Pró-Índio do Acre, de um lado, e, de outro, pelo documentarista, professor e parceiro dos artistas Kaxinawá em suas pesquisas, Amilton de Mattos. A obtenção de financiamento junto à Faperj ${ }^{5}$ possibilitou, em 2014, a realização de uma viagem de pesquisa em que foi reunido um conjunto de gravações em Português Kaxinawá, efetuadas nas cidades de Cruzeiro do Sul, Marechal Thaumaturgo e nas cinco aldeias da TI Kaxinawá-Ashaninka do Rio Breu. Cuidadosamente analisados a partir dos referenciais teórico-metodológicos da Teoria da Variação e da Mudança de inspiração laboviana (Tarallo 1990; Labov 1994; Scherre 1994; Pagotto 2006; Guy e Zilles 2007), esses dados evidenciaram particularidades do Português Kaxinawá, como a existência de sentenças transitivas com verbo na última posição (o que corresponde à ordem sintática canônica nas línguas Pano) e a possibilidade de marcação expressa de plural unicamente no último elemento do sintagma nominal (como em "nosso arrecurso naturais", o que, provavelmente, se liga ao fato de o morfema - nãoobrigatório - de plural - bu do Kaxinawá ligar-se ao núcleo ou ao modificador de um sintagma nominal).

Identificou-se, ainda, em determinados contextos, uma maneira de estabelecer a concordância de gênero no sintagma nominal que sugere uma estratégia própria de delimitação de constituintes, distinta daquela empreendida por falantes nativos do Português Brasileiro. Nesse padrão inserem-se sintagmas como "essa tipo de inveja", "a preço da borracha", "dessa levantamento das música", "a manejo da caça" e "os música de batismo", em que postulamos que o vocábulo fonológico, percebido como uma única unidade, teve a concordância de gênero norteada, por assim dizer, pelo gênero do elemento situado na extremidade da direita do sintagma nominal ${ }^{6}$. Acreditamos, nessa mesma direção, que a natureza aglutinante das línguas Pano teria favorecido o tratamento do vocábulo fonológico também como uma unidade de caráter morfossintático.

5 Processo n. ${ }^{\circ}$ E-26/ 111.344/2013, edital APQ1.

6 Vale ressaltar que a extremidade da direita dos sintagmas abriga os morfemas responsáveis por assegurar a gramaticalidade de estruturas linguísticas, especialmente nos sintagmas verbais, na língua Kaxinawá. 
As entrevistas sociolinguísticas coletadas em 2014, que nos revelaram as estruturas linguísticas apontadas logo acima, nos levaram a atentar, também, para aspectos da tessitura das interações comunicativas e para o modo como os Kaxinawá se engajavam na distribuição de tópicos discursivos e turnos de fala. Conforme abordado em Christino (2018), mostraram-se recorrentes naquelas interações entre pesquisadora e colaboradores Kaxinawá, em especial, dois procedimentos interacionais por parte dos falantes de Português Kaxinawá: (a) o emprego de retomadas da fala do outro, como estratégia de início de turno de fala e (b) a utilização do que viemos a denominar de 'fórmulas de fechamento'. Diante disso, passamos a considerar que traços da etiqueta interacional própria dos Kaxinawá poderiam marcar presença também em interações transculturais, nas quais se lança mão do Português como língua veicular. Essa linha de interpretação ganhou força, pois, segundo o que temos observado, as retomadas da fala do outro e, em especial, as fórmulas de fechamento praticamente não são empregadas pelos não-indígenas do Alto Juruá (v. Peres da Costa 2018; Peres da Costa 2019).

No âmbito deste artigo, temos a intenção de caracterizar, em mais detalhes, as fórmulas de fechamento, de modo a empreender um desdobramento da análise desenvolvida em Christino (2018). Os referenciais teórico-metodológicos norteadores desse processo de investigação encontram-se explicitados na próxima seção.

\section{Analisando Aspectos Discursivo-Interacionais do Português Kaxinawá: Referenciais Teóricos e Metodologia}

Uma vez investigando aspectos discursivos e interacionais do Português Kaxinawá, já não nos contemplavam os referenciais teórico-metodológicos da sociolinguística laboviana, que foram basilares para as análises de cunho morfossintático. Dessa forma, buscamos, nessa segunda fase da pesquisa, nos apoiar em referenciais da Sociolinguística Interacional (Ribeiro e Garcez 2013), assim como da Análise da Conversação (Fávero 1995; Galembeck 1995; Jubran et. al 2002) para dar continuidade, embora imprimindo uma nova direção, à investigação do Português Kaxinawá.

Nesse movimento, procuramos analisar, principalmente, aspectos referentes à distribuição de turnos de fala durante a interação, assim como a estratégias de delimitação tópica. Tomamos o tópico discursivo como "uma questão de conteúdo, estando na dependência de um processo colaborativo que envolve os participantes no ato interacional" (Fávero 1995, 38), de modo que o critério de "centração" se mostra como definidor da noção de tópico. Ademais, entendemos turno como "qualquer intervenção dos interlocutores (participantes do diálogo), de qualquer extensão" (Galembeck 1995, 60), abrangendo, desse modo, tanto 
os enunciados propriamente referenciais ou informativos, quanto intervenções breves com o intuito de demonstrar interesse ou fornecer pistas meta-discursivas.

Aclaradas as noções de tópico e turno, fundamentais para nossa análise, lancemos um olhar mais atento a processos em jogo durante a interação facea-face. Assim, levamos em consideração que, em situações comunicativas específicas, participantes de diferentes culturas tendem a mobilizar esquemas de conhecimento e enquadres interativos igualmente específicos (Tannen e Wallat 1987, 183-214), de modo a melhor se adequarem aos eventos comunicativos em questão. Tais esquemas e enquadres são, por sua vez, negociados ao longo da interação através de pistas de contextualização (Gumperz 1982, 149-182) linguísticas, como mudança de código ou expressões pré-formuladas; e com base em uma série de pistas para-linguísticas, tais quais mudanças na entonação, silêncios e hesitações; ou não verbais, como alterações na postura, olhares e gestos. É preciso ressaltar que o valor atribuído a essas pistas afigura-se culturalmente estabelecido e variável, pressupondo-se, em interações interétnicas, um ainda maior movimento de negociação, além de uma considerável possibilidade de se estabelecerem conflitos e descompassos.

No que tange a pistas linguísticas presentes na interação, Jubran et al. (2002, 341-420) investigam cuidadosamente a organização tópica da conversação, empreendendo a identificação de marcadores linguístico-discursivos de delimitação tópica. Segundo as autoras, que estudam interações entre falantes de Português Brasileiro como primeira língua, as aberturas e fechos de tópicos conversacionais podem ser, por vezes, reconhecidas por meio de marcas, classificadas pelas pesquisadoras em prosódicas (como alterações na entonação); morfossintáticas (tais quais estruturas de topicalização); léxico-semânticas (como enunciados conclusivos e estruturas cristalizadas de fecho); ou ainda pausas, hesitações e outras marcas discursivas, como perguntas retóricas. Para exemplificar algumas dessas categorias, faremos uso de trechos constantes de nosso conjunto de entrevistas sociolinguísticas. Sendo assim, "o primeiro mesmo ele tava doente de malária" ou "agente de saúde ele sempre fala pra nós que, pra nós organizar a nossa casa" contém estruturas de topicalização (em destaque); "aí é muito difícil" representa um caso de enunciado conclusivo, enquanto "pois é, é isso" enquadra-se entre as estruturas cristalizadas de fecho.

Jubran et al. (2002) enfatizam, igualmente, que essas marcas são, de um lado, facultativas, podendo haver mudança de tópico sem que haja uma marca explícita associada e, de outro, multifuncionais, de modo que as mesmas estruturas utilizadas para delimitação tópica podem ser usadas para outros fins. O advérbio "então", por exemplo, revela essa multifuncionalidade, uma vez que pode atuar como: iniciador de um tópico, elemento que estabelece relações lógico-semânticas no campo da estruturação sintática ou conector de uma sequência de eventos narrativos. Além disso, as autoras apontam que tais marcas podem revelar-se co-ocorrentes, ou seja, há a possibilidade de mais de 
uma marca aparecer por fronteira de tópico, o que inclui combinações, muitas vezes, de elementos segmentais e suprassegmentais.

Nossa intenção de reconhecer possíveis traços discursivo-interacionais próprios da cultura Kaxinawá na participação de falantes bilíngues em interações transculturais toma por base análises como a de Philips (1976, 21-43). Essa pesquisadora, a partir de seu estudo sobre interações entre anglo-americanos, de um lado, e entre indígenas Sahaptin e Chinookan da reserva de Warm Springs no Oregon (EUA), de outro, sublinha a existência de variabilidade cultural na maneira como os falantes instauram processos de comunicação verbal e não verbal. A autora ressalta, entre outros aspectos, que a gestão de turnos conversacionais pelos Sahaptin e Chinookan é consideravelmente diferente daquela característica entre os anglo-americanos. De acordo com suas observações, os indígenas Sahaptin e Chinookan não costumam interromper o turno conversacional alheio nem selecionar ouvintes específicos para a tomada do próximo turno e não contam, necessariamente, com uma resposta imediata. Em sua convivência com a comunidade da reserva de Warm Springs, Philips (1976) pôde observar respostas sendo oferecidas vários turnos após a formulação da pergunta correspondente e, até mesmo, vários dias depois.

No cenário brasileiro, Maher (1994, 69-77) realiza análise comparável ao trabalhar com professores indígenas do Acre em formação, entre os quais muitos eram Kaxinawá ${ }^{7}$. A partir de oficinas visando à elaboração de material didático para o ensino de Português nas escolas indígenas, a pesquisadora se defronta com notáveis diferenças entre os padrões interacionais dos professores indígenas e os seus próprios. Ela veio a perceber, por exemplo, que, da parte dos professores indígenas, era esperado que uma resposta não fosse dada de forma direta, mas que contivesse, como introdução, alguma forma de retomada da fala do interlocutor. Convenções culturais dessa natureza ligam-se ao campo da etiqueta interacional, assim definido por Maher:

As pessoas falam diferente, não só porque utilizam sistemas gramaticais diferenciados, mas também, porque seguem convenções pragmáticas diferenciadas. Cada cultura imprime na sua língua um código de conduta interacional específico, e seus falantes seguem tais scripts culturais de modo a se comportarem apropriadamente nos diferentes contextos interativos. (Maher 1994, 76, ênfases adicionadas).

Partindo da hipótese que, mesmo em interações interétnicas, os Kaxinawá continuariam resguardando em sua variedade de Português traços de sua etiqueta interacional, e tomando como unidades centrais de análise as noções de tópico e turno, buscamos investigar, mais profundamente, a ocorrência das construções

7 Além dos Kaxinawá, também participaram desses cursos professores Apurinã, Manchineri, Jaminawa, Shawandawa, Yawanawa, Katukina e Poyanawa (Maher 1994, 69). 
que denominamos 'fórmulas de fechamento'. Para tanto, examinamos o corpus levantado a partir das entrevistas sociolinguísticas gravadas no Alto Juruá em 2014. Essas entrevistas foram transcritas grafematicamente por integrantes de nosso grupo de pesquisa e, posteriormente, revistas por outros integrantes.

Optou-se, nesse processo de transcrição e revisão, por adotar as convenções ortográficas por três motivos: (1) por não haver fenômenos fonéticofonológicos em investigação; (2) por esta forma de transcrição não inviabilizar o reconhecimento de particularidades morfossintáticas (caso da ausência de concordância de gênero, v. Christino 2015; e da presença de marca de plural em sintagma nominal com núcleo singular, v. Christino e Silva 2017) e, principalmente, (3) para que a transcrição pudesse ser acessível a todo Kaxinawá alfabetizado em língua portuguesa. Como Garcez (2002), acreditamos que não exista uma transcrição ideal, dada de antemão, e que "devemos estar criticamente conscientes das implicações teóricas, políticas e éticas de nosso processo de transcrição e dos produtos finais que dele resultam." (Garcez 2002, 84) ${ }^{8}$

No processo de transcrição dos dados linguísticos, foram observadas, ainda, as seguintes convenções: [...] para indicar trecho suprimido; $[\mathrm{xxx}]$ para indicar comentário do transcritor; 'xxx' para indicar discurso direto; [INC] para indicar trecho incompreensível; ponto de interrogação (?) para indicar entoação ascendente; barra (/) para indicar quebra sintática; vírgula (,) para indicar pausa de menos de dois segundos e reticências (...) para indicar pausa de mais de dois segundos. A pesquisadora é referida por 'B' e os participantes Kaxinawá por duas letras, de modo a preservar suas identidades.

Concluída a etapa de revisão das transcrições, reuniu-se um conjunto de vinte entrevistas sociolinguísticas, nas quais foram identificadas as fronteiras de turno de fala. Paralelamente, foi observado, de forma detida, cada um dos pares adjacentes de pergunta-resposta e o modo como se distribuíam os tópicos discursivos. Com isso, pudemos realizar um levantamento exaustivo dos processos de retomada da fala do outro (de que não nos ocuparemos, por questões de espaço, no presente artigo) e das estruturas formulaicas de fecho de tópico e turno. A análise dessas últimas, construídas com os operadores "isso" e "assim" - como se vê em "[...] é tudo isso minha apresentação" e em "[...] assim que nós funciona nossa terra indígena" - representa o foco da seção 4.

\section{4. "É Assim": Estrutura e função das fórmulas de fechamento}

Mesmo antes da realização de nosso levantamento exaustivo dos pares pergunta-resposta e dos processos de alternância de tópico discursivo, chamou nossa atenção a presença recorrente de estruturas cujo comportamento não só lembrava as construções próprias para finalização de tópicos discursivos reconhecidas por Amado (2015) no Português Timbira, como também,

8 Trata-se, como indicado por Garcez (2002), de uma tradução livre de Duranti (1997). 
significativamente, se assemelhavam a estruturas empregadas no encerramento de narrativas em Kaxinawá. De acordo com o que destacou Christino (2018), tanto narrativas míticas e tradicionais registradas por João Capistrano de Abreu (1853-1927), no início do século XX (v. Abreu 1914), quanto narrativas recolhidas e transcritas por Camargo \& Villar (2013) apresentam tais estruturas.

Com efeito, uma comparação entre os elementos em negrito: a) em (1) e (2), que integram nosso corpus de análise; b) em (3) e (4), constantes da obra assinada por Capistrano de Abreu, e c) em (5) e (6), encontrados no livro organizado por Eliane Camargo e Diego Villar, torna evidente a sua similaridade.

1) (AB) o roçado de primeiro assim a gente brocava não tinha é... não tinha consulta né, agora hoje em dia tem a capoeira, mas tem que consultar hã... onde tem medicina não pode derrubar mais [...] assim que nós funciona nossa terra indígena

2) (MX) quando a gente, alguém fala, nós fala 'mulherada bora fazer assim, bora fazer assim, bora fazendo, bora pegar cerâmica, bora pegar cestinha pra fazer', ai a gente vai junta, gente pega e senta na escola ai vai fazendo, é assim nós trabalha

3) "bônirã raç'kamiç'bôki."/ "fome têm, assim fazem." (Abreu 1914, 67)

4) "raç'kamiç'bôki in nabôrã."/ "assim fazem minhas gentes."(Abreu 1914, 126).

5) "Haska en uintanimaki nawabu hiweabudan"/ "Assim conheci a vida dos nauás das grandes cidades" (Villar e Camargo 2013, 225)

6) "Haskai unu manankidi Kudan henwen hiweakiki"/ "É assim que vivem os maxicos do alto Curanja" (Villar e Camargo 2013, 163)

Além de presente em (1) e (2), o operador discursivo "assim", não por acaso, foi a escolha de Abreu (1914) e de Camargo e Villar (2013) para servir de tradução (de acordo com as convenções gráficas adotadas pelos pesquisadores) para raç'ka (-i)/ haska (-i), como se nota em (3) a (6). Em nossa descrição das fórmulas de fechamento, abordamos, também, as construções com "isso", que revelaram configuração estrutural e função, no desenvolvimento da interação, em tudo equivalentes às das fórmulas negritadas em (1) e (2).

Nosso levantamento revelou um conjunto de 190 ocorrências dessas estruturas cristalizadas de fecho. Bastante recorrentes entre os colaboradores Kaxinawá de nossa pesquisa, essas fórmulas apareceram em dezoito das vinte entrevistas sociolinguísticas analisadas. Em (7) e (8) podem-se identificar exemplos do contexto de uso dessas fórmulas, marcadas em negrito. 
7) (B) e o que que você quer fazer, o que que você tem de plano? (AS) eu tenho de plano... eu quero fazer no meu pesquisa como medicina tradicional pra fazer cura no meu povo minha comunidade e todo terra indígena pra aquele que tem algumas coisas tem que fazer alguns medicamentos tem que fazer alguns agradecimento também né, então o meu pensamento é assim, como meu formação como agente saúde né como até como nós como nós equilibrado como huni kuin nauá como, em português né, nós tamo junto como alguns pessoas sentindo alguns problema tem que fazer cura tem que fazer uns dá medicamento pra fazer com/ junto com alegria junto com/ junto com ele pra saber aquele formação né, isso que eu tô pensando

8) (B) como que tá a organização das festas tradicionais?

(FB) ah, festa né... festa é assim aqui nós tem um, nós tem um ra... [...] eu sei que sobre o negócio de/ de cultura de/ de katxanawa nunca perdemo não, nós nunca perdemo não graças a deus sempre a gente... a gente dança mariri, então as criancinhas, como... como você viu quando chegou ali, aí tem um velhinho ali que ensina também né, aí dia de sábado né fica ensinando as criança né pra elas ficar não mais perdido com... como eu falei né com negócio de remédio tradicionais né, assim as criança vão aprender também né, isso aí a cultura não acaba mais né, quando eles tudo fica grande, tudo já sabe né e as coisa continua né... é isso negócio de katxanawa

Em (7), o falante constrói duas fórmulas de fechamento, uma no interior e outra no final de seu turno de fala, fazendo referência, nos dois momentos, à própria construção discursiva, através das expressões "meu pensamento" e "isso que eu tô pensando". Em (8), por sua vez, há uma fórmula de fechamento que faz referência ao tópico discursivo desenvolvido. Nesse caso, uma das festas tradicionais dos Kaxinawá, o katxanawa, ritual da fertilidade (v. Lagrou 1991, 88).

A observação cautelosa das fórmulas de fechamento nos sugeriu que elas pudessem cumprir a função de encerramento tanto de turno de fala quanto de tópico discursivo, o que se coaduna com o caráter multifuncional dos marcadores linguístico-discursivos, de acordo com Jubran et al. (2002). Sendo assim, em um primeiro momento, realizamos um levantamento referente à localização das fórmulas de fechamento, ou seja, verificamos se as fórmulas marcavam presença no final de turnos de fala (como o segundo exemplo de (7)), podendo, assim, atuar como uma pista de que o falante acabara de falar e passava o turno à sua interlocutora; ou se elas apareciam durante o desenvolvimento do turno do falante (caso do primeiro exemplo de (7)), marcando, possivelmente, o encerramento de um tópico ou subtópico conversacional. Registrando os resultados dessa verificação, a tabela 1 apresenta, para cada falante, o número de ocorrências de fórmulas de fechamento em final e em interior de turno. A 
disposição dos dados abaixo obedece à ordenação crescente de quantidade de ocorrências por falante.

Tabela 1: Ocorrências de fórmulas de fechamento por falante e sua localização

\begin{tabular}{|c|c|c|c|c|c|c|c|}
\hline Falante & $\begin{array}{c}\text { Interior de } \\
\text { T. }\end{array}$ & $\begin{array}{c}\text { Fim de } \\
\text { T. }\end{array}$ & Total & Falante & $\begin{array}{c}\text { Interior } \\
\text { de T. }\end{array}$ & $\begin{array}{c}\text { Fim de } \\
\text { T. }\end{array}$ & Total \\
\hline AP & 0 & 0 & 0 & VB & 4 & 4 & 8 \\
\hline PT & 0 & 0 & 0 & RH & 0 & 9 & 9 \\
\hline EH & 0 & 2 & 2 & RI & 6 & 4 & 10 \\
\hline AC & 0 & 3 & 3 & FH & 7 & 4 & 11 \\
\hline GS & 0 & 4 & 4 & GP & 1 & 10 & 11 \\
\hline AH & 2 & 3 & 5 & AS & 4 & 9 & 13 \\
\hline TE & 1 & 4 & 5 & ZM & 8 & 6 & 14 \\
\hline MY & 0 & 6 & 6 & PE & 9 & 7 & 16 \\
\hline MX & 0 & 7 & 7 & FB & 13 & 13 & 26 \\
\hline TJ & 1 & 6 & 7 & AB & 11 & 22 & 33 \\
\hline Falante & Interior de & Fim de & Total & & & & \\
\hline TOTAL & $\mathbf{6 7}$ & $\mathbf{1 2 3}$ & $\mathbf{1 9 0}$ & & & & \\
\hline \% & $\mathbf{3 5 . 3 \%}$ & $\mathbf{6 4 . 7 \%}$ & $\mathbf{1 0 0 \%}$ & & & & \\
\hline
\end{tabular}

Como nos mostra a tabela 1, todos os dezoito colaboradores Kaxinawá que empregaram as fórmulas de fechamento utilizaram-nas, pelo menos duas vezes, ao final de um de seus turnos de fala. As fórmulas de fechamento em final de turno, aliás, corresponderam às de maior frequência, alcançando $64.7 \%$ do total. As 67 ocorrências de fórmulas de fechamento não-coincidentes com conclusão de turno de fala (35.3\% do total) distribuíram-se entre 12 falantes e tiveram lugar, principalmente, quando o falante termina um subtópico, utilizando uma fórmula de fechamento e, em seguida, aborda um novo subtópico dentro de um mesmo macrotópico (o que se verifica em (9)).

9) (B) e pra caçar como é que aprende?

(FB) sim, caçar assim, começa a aprender com o pai, a criança com dez ano, 'papai quero ir também', o pai vai caçar né. 'ah, eu quero ir' 'quer ir? então bora' aí leva, vai começando conhecer o pique que... o pai vai caçando, vai conhecendo... [...] quem começa ensinar é o pai, aí bem pro fim quando já tá grande não vai mais mais o pai não, ele já sabe caçar, às vez vai só, vai com os irmão dele é assim, pra caçar é isso... e outra coisa que eu gosto de falar mesmo... coisa contar mesmo, eu acho que você já sabe mais ou menos também aqui quando eles caça, traz a caça né... às vez nós divide, aquele que não dividiu pra todo mundo aí chama todo mundo, todo 
mundo vamo comer no cupixaua, todo mundo a gente vai comer no cupixaua, pode ser criança, tudo, adulto, tudo, é assim, por isso que a gente tem o cupixaua, é isso

Como se pode notar em (9), o falante, no âmbito do macrotópico "caça", trata inicialmente do subtópico "aprendizado da caça". Após detalhar como as crianças aprendem a caçar, ele emprega a fórmula de fechamento "é assim, pra caçar é isso", e logo em seguida inicia o subtópico "distribuição da caça", quando explica que, uma vez obtida, a caça é levada ao cupixaua ${ }^{9}$ para ser dividida entre todos da comunidade. Ao final desse subtópico, o falante emprega novamente uma fórmula de fechamento, coincidindo, dessa vez, com o encerramento de seu turno de fala.

Analisando as configurações das fórmulas de fechamento presentes no conjunto de gravações em foco, percebemos que algumas incluíam em sua estrutura uma retomada do tópico discursivo (caso de (10), abaixo, assim como de (8), acima), o que vem a reforçar que sejam vistas como marcadores de fim de tópico. Noutros casos, há uma menção explícita à situação comunicativa e à alternância de papéis na conversação, contribuindo para a interpretação dessas estruturas também como sinalizadores de final de turno de fala, conforme exemplifica (11).

(10) B) quem que toca forró lá na sua aldeia?

(AB) forró lá, é aluno né, às vez gravador, comprava no tempo que não tinha isso, tinha um bolsinho, tinha salário de aposentado comprava seu gravador, coloca a fita e funciona né, assim funciona hã... forró (risos)

11) (GS) [...] eu tenho cinquenta e três ano, trabalhei, eu venho trabalhando como agente de saúde da comunidade e eu continua trabalhando e eu dei meu trabalho pro meu filho mais velho, né, como cuidar, como saúde da/ dos meus parente, né, da comunidade e o meu trabalho que eu me interessei de trabalhar outras coisa, ajudando meu povo, né, eu de extrair os dente, dentista... é só isso que eu queria dizer

Em (10), o falante claramente retoma o tópico discursivo "forró" em seu fechamento de turno de fala, enquanto, em (11), o parceiro interacional Kaxinawá termina sua apresentação inicial fazendo menção ao próprio ato comunicativo com a expressão "é só isso que eu queria dizer". Em função de sua natureza metadiscursiva, podem ser associadas à fórmula de fechamento observável em (11), aquelas em que o falante de Português Kaxinawá faz uma

9 Cupixaua é uma palavra, com origem na Língua Geral Amazônica, utilizada em variedades de português do norte do Brasil para designar uma construção não residencial de grandes dimensões em que se desenvolvem atividades coletivas, como festas tradicionais, rituais e reuniões políticas. 
menção explícita à atividade cognitiva vinculada ao ato comunicativo. É o que se pode verificar no excerto (7), acima, e nas expressões em destaque em (12) e (13).

12) (EH) [...] nós vem passear não, nós que busca semente pra nós colocar a nossa aldeia tudos comunidade tudos terra indígena... se o pessoa, é... o professor e o agente de saúde, liderança, concordaram ser nosso trabalho, nós trabalha junto com tudos terra indígena, aí nós vem buscar esse semente pra nós semear tudo a terra indígena, só isso que é meu ideia

13) (FH) $[\ldots]$ o tamanho dos pinto que vai comprando né, então isso foi mais sofrido, ainda tem as coisa pra... pra resolver, né, sobre alevino, né, essa alevino vai ser mais trabalho também, né, porque não pode demorar mais muito tempo, tem que chegar mesma hora já pode deixar no açude, né, então onde eu posso... qual o apoio que eu posso de receber, quem que pode ajudar o prefeito, o governador, se tu fosse poder ajudado, né, então isso é eu pensa isso, tô aqui pra já resolvendo essa parte aí

Focalizando a configuração estrutural das fórmulas de fechamento, também foi possível notar algumas peculiaridades acerca do uso dos operadores "isso" ou "assim". Cabe destacar que, dependendo do falante, percebeu-se, na maioria dos casos, uma clara preferência pelo emprego de um operador específico. Isso pode ser facilmente constatado na tabela 2 , que registra, para cada falante, o número de fórmulas utilizadas com cada operador. Assim como na tabela 1 , a exposição dos dados reflete a ordenação crescente de quantidade de ocorrências de fórmulas de fechamento por falante.

Tabela 2: Ocorrências de fórmulas de fechamento por falante e operador

\begin{tabular}{|c|c|c|c|c|c|c|c|}
\hline Falante & ISSO & ASSIM & Total & Falante & ISSO & ASSIM & Total \\
\hline AP & 0 & 0 & 0 & VB & 1 & 7 & 8 \\
\hline PT & 0 & 0 & 0 & RH & 8 & 1 & 9 \\
\hline EH & 2 & 0 & 2 & RI & 10 & 0 & 10 \\
\hline AC & 1 & 2 & 3 & FH & 11 & 0 & 11 \\
\hline GS & 3 & 1 & 4 & GP & 10 & 1 & 11 \\
\hline AH & 1 & 4 & 5 & AS & 9 & 4 & 13 \\
\hline TE & 1 & 4 & 5 & ZM & 13 & 1 & 14 \\
\hline MY & 6 & 0 & 6 & PE & 15 & 1 & 16 \\
\hline MX & 1 & 6 & 7 & FB & 18 & 8 & 26 \\
\hline TJ & 6 & 1 & 7 & AB & 2 & 31 & 33 \\
\hline
\end{tabular}


Dos vinte falantes considerados, quatro enunciaram apenas fórmulas construídas com o operador "isso" (EH, MY, RI e GP), ao passo que onze utilizaram majoritariamente um dos operadores, fazendo uso do outro somente em uma das ocorrências. Sendo assim, AC, AH, TE, MX e VB valeramse, predominantemente, de "assim", enquanto, GS, TJ, RH, GP, ZM e PE empregaram, quase que exclusivamente, "isso". Tais padrões de distribuição corroboram a hipótese de que essas estruturas sejam formulaicas, à medida que os dados reunidos sugerem que os falantes tendem a preferir uma mesma configuração estrutural em suas fórmulas de fechamento.

Outro aspecto que reforça o caráter formulaico e a ausência de conteúdo informacional que caracterizam as fórmulas de fechamento é o fato de que, das 190 ocorrências encontradas nas entrevistas sociolinguísticas, 46 (24\%) foram construídas apenas com o verbo cópula "ser" seguido dos operadores "isso" ou "assim". Em (14) e (15) exemplifica-se esse processo.

14) (B) e como que tá a saúde aqui?

(GP) saúde é... começou foi... parece que foi em 98 que começou... [...] hoje tá... entrou um um jovem que tem muita dificuldade de tá trabalhando na parte de saúde hoje e nesse o pessoal também tão vendo que ele tá trabalhando certo né, precisa muito de tá participando mesmo no curso assim no treinamento né pra poder trabalhar na sala... na parte de saúde né, é isso

15) (B) e o que que você pede pros alunos fazerem?

(AC) eu pede pra fazer, fez aqui pra... mandar eu completar frase pra completar a letra do animal é assim né

Doze dos nossos vinte colaboradores Kaxinawá lançaram mão de fórmulas de fechamento construídas apenas com o verbo cópula e os operadores "isso" ou "assim" (como em (14) e (15)). Reconhecíveis em vários dos excertos já apresentados, as fórmulas de fechamento com configurações mais complexas marcaram presença na fala de todos os dezoito colaboradores que fizeram uso das fórmulas de fechamento. Além das fórmulas de fechamento com configuração estrutural mais complexa que fazem referência ao tópico discursivo (caso de (8) e (10)) e daquelas que contêm comentários metadiscursivos (como se pôde ver em (7), (11), (12) e (13)), observaram-se, também, fórmulas do tipo mais complexo que não retomavam explicitamente elementos do tópico discursivo e nem faziam menção à situação comunicativa:

16) (B) e o que que é o nixi pae? pra quem não sabe.

(TJ) nixi pae é::, Santo Daime, pajé pra/ pra fazer preparo né, junto com os/ todo representante os aluno jovem cada vez aprendem mais né, mestre é nós/ nós vamo capacitando isso, cada grupo cada aldeia... cantando música de cura né, nos/ a gente faz assim, na nossa aldeia 
17) (B) como funciona essa merenda natural?

(RI) merenda natural é lá.. .é o que nós plantamos né, que nós planta os legume, aí é:... nós que abastecemo a escola né [...] aí cada pessoa tem seu/ sua cozinhazinha, lá, acho que tu viu né, onde fornece merenda né, [...] isso também é merenda aqui que sobra (risos)

(B) ah, é? como é que fala?

(RI) é como eu fa/ eu fala, tem bastante ingá, deixa pros menino comer a vontade mesmo, e assim melhor né, [...] então, aí visto desse lado, a gente tem essa merenda na nossa aldeia né, aí todo final de mês a gente se reúne também né, que foi feito, foi bom ou não, se precisa melhorar também, gente faz essa parte né, caso dos legume que gente... isso, pra saúde, também, tudo tranquilo né, pra nós isso que funciona

Em (16), o falante termina o tópico "nixi pae" junto com seu turno, concluindo com a fórmula de fechamento "a gente faz assim, na nossa aldeia", em que não se menciona expressamente o tópico discursivo. Por sua vez, em (17), o primeiro turno de fala transcrito conta com uma fórmula de fechamento que remete, de forma direta, ao tópico "merenda" (assim como os tópicos "katxanawa" e "forró" encontravam-se incluídos nas fórmulas de fechamento, respectivamente, de (8) e (10)). Em face da pergunta "como é que fala" de sua interlocutora, o falante dá continuidade a esse tópico e vem a finalizar seu turno de fala com a fórmula de fechamento "pra nós isso que funciona", sem fazer qualquer referência direta ao tópico discursivo "merenda".

A análise das chamadas fórmulas de fechamento em Português Kaxinawá, apresentada nessa seção, evidenciou que tais construções seguem, de modo claro, um padrão. Como se pôde constatar, essa uniformidade abrange tanto a dimensão de sua configuração estrutural quanto o seu papel no desenvolvimento da interação, uma vez que, sistematicamente, sinalizam a conclusão de tópicos (ou subtópicos) discursivos e de turnos de fala.

\section{Conclusão}

Bastante similares a estruturas formulaicas recorrentes em narrativas em Kaxinawá e (ao que nossas observações vêm indicando) sem paralelo no Português (L1) do Alto Juruá, as fórmulas de fechamento examinadas, possivelmente, configuram um elemento da etiqueta interacional própria dos Kaxinawá a marcar presença nas interações transculturais.

$\mathrm{Na}$ mesma medida em que não há como considerar fortuita a semelhança entre as fórmulas de fechamento reconhecíveis nas narrativas registradas por Abreu (1914) e Camargo e Villar (2013) e enunciados como "assim que nós funciona nossa terra indígena", fica patente que, para se fazer afirmações mais seguras acerca do papel das fórmulas de fechamento na dinâmica interacional dos 
falantes de Português Kaxinawá, são imprescindíveis pesquisas complementares que possam abranger eventos comunicativos de diferentes gêneros discursivos (para muito além das entrevistas sociolinguísticas). Nesse sentido, ganhariam particular relevância registros de interações transculturais vinculados a variadas formas de organização das relações de poder entre os interlocutores.

\section{Referências}

Abreu, João Capistrano de. 1914. rã-txa hu-ni-ku-in. A língua dos caxinauás do rio Ibuaçú, affluente do Murú (Prefeitura de Tarauacá). 1 ${ }^{\mathrm{a}}$ ed. Rio de Janeiro: Typografia Leuzinger.

Amado, Rosane de Sá. 2015. O português étnico dos povos Timbira. Papia-Revista Brasileira de Estudos Crioulos e Similares 25.1: 103-119.

Camargo, Eliane. 2013. "Introdução". In: Camargo, Eliane e Villar, Diego (orgs.). Huni Kuin Hiwepaunibuki. A história dos Caxinauás por eles mesmos. La historia de los Cashinahuas por ellos mismos, 43-47. São Paulo: Edições Sesc.

Camargo, Eliane; Villar, Diego (orgs.). 2013. Huni Kuin Hiwepaunibuki. A história dos Caxinauás por eles mesmos. La historia de los Cashinahuas por ellos mismos. São Paulo: Edições Sesc.

Christino, Beatriz. 2015. Gender agreement in Huni Kuin Portuguese noun phrases. Papia, v. 25, nº. 1: 77-102.

Christino, Beatriz. 2018. "Hoje não somos Huni Kuin só na nossa língua”: o português kaxinawá em interações transculturais. Trab. Ling. Aplic., Campinas, $n^{\circ}$. 57.3, set/ dez: 1486-1511.

Christino, Beatriz; Lima e Silva, Moana de. 2012. Concordância verbal e nominal na escrita em Português Kaingang. Papia, v. 22, nº. 2: 415-428.

Christino, Beatriz; Silva, Amanda de Matos. 2017. A expressão de plural em Português Huni-Kuin: um exame dos sintagmas nominais, Letrônica 10/1: 30-45.

Costa, Januacele Francisca da. 1993. Bilingüismo e atitudes lingüísticas interétnicas. Aspectos do contato Português-Yathê. Dissertação de Mestrado, Universidade Federal de Pernambuco.

Fávero, Leonor Lopes. 1995. "O tópico discursivo". In: Preti, Dino. Análise de textos orais: 33-55.

Ferreira, Marília. 2005. Descrição de aspectos da variante étnica usada pelos Parkatêjê. DELTA: Documentação de Estudos em Lingüística Teórica e Aplicada 21.1: 1-21.

Galembeck, Paulo de Tarso. 1995. "O turno conversacional”. In: Preti, Dino. Análise de textos orais: $55-80$.

Garcez, Pedro M. 2002. "Transcrição como teoria: a identificação dos falantes como atividade analítica plena". In: Luiz Paulo da Moita Lopes \& Liliana Cabral Bastos (orgs.) Identidade: Recortes Multi e Interdisciplinares, 83-95. Campinas/ CNPq: Mercado de Letras. 
Gumperz, John Joseph. 1982. “Convenções de Contextualização”. In: Ribeiro, Branca Telles; Garcez, Pedro M. 2013. Sociolinguística Interacional, 149-182. 2a ed. São Paulo. Loyola.

Guy, Gregory; Zilles, Ana. 2007. Sociolingüística quantitativa - Instrumental de análise. São Paulo: Parábola.

Iglesias, Marcelo Manuel Piedrafita. 2008. Os Kaxinawá de Felizardo: correrias, trabalho e civilização no Alto Juruá. Tese de Doutorado em Antropologia Social. Museu Nacional, Universidade Federal do Rio de Janeiro, Rio de Janeiro.

Jubran, Clélia Candida Abreu Spinardi, et al. 2002. "Organização tópica da conversação". In: Ilari, Rodolfo (Org.). Gramática do português falado, Volume II: Níveis de análise linguística, 341-420. $4^{\mathrm{a}}$ ed. Unicamp.

Labov, William. 1994. Principles of Linguistic Change. Volume 1: Internal Factors. Oxford/ Cambridge: Blackwell.

Lagrou, Elsje Maria. 1991. Uma etnografia da cultura Kaxinawá: entre a cobra e o inca. Dissertação (Mestrado em Antropologia Social) - UFSC, 1991. Disponível em: $<$ https://repositorio.ufsc.br/handle/123456789/75772> . Acesso em: 2 out. 2019.

Maher, Terezinha de Jesus Machado. 1994. O ensino de língua portuguesa nas escolas indígenas. In: Em Aberto, 69-77. ano 14, n.63, jul./set, Brasília.

Maher, Terezinha de Jesus Machado. 1996. Ser professor sendo índio: questões de língua(gem) e identidade. Tese de Doutorado, Instituto de Estudos da Linguagem/ Unicamp.

Maher, Terezinha de Jesus Machado. 1998. "Sendo índio em português...". In: Signorini, Inês (org.). Língua(gem) e identidade. Elementos para uma discussão no campo aplicado. Campinas: Mercado de Letras/Fapesp.

Maná Kaxinawá, J. P. et al. 2002. Índios no Acre - Organização e história. Rio Branco: Comissão Pró-Índio do Acre.

Mattos e Silva, Rosa Virgínia. 1988. Sete estudos sobre o português Kamayurá. Salvador: Centro Editorial e Didático da UFBa.

Ministério da Educação. Secretaria de Educação Fundamental. 1998. Referencial Curricular Nacional para as Escolas Indígenas. Brasília.

Pagotto, Emilio Gozze. 2006. "Sociolinguística”. In: Pfeiffer, C. C. \& Nunes, J. H. (Org.). Introdução às ciências da linguagem - linguagem, história e conhecimento, 49-72. Campinas, Pontes.

Peres da Costa, João Pedro. 2018. Uma análise comparativa da etiqueta interacional de Kaxinawás e Não-indígenas no Alto Juruá. Comunicação apresentada na IX Semana de Integração Acadêmica, UFRJ.

Peres da Costa, João Pedro. 2019. Marcadores Linguísticos de Delimitação Tópica em Português Kaxinawá e Português L1 do Alto Juruá. Comunicação apresentada na X Semana de Integração Acadêmica, UFRJ.

Philips, Susan. 1976. "Algumas fontes de variabilidade cultural na ordenação da fala". In: Ribeiro, Branca Telles; Garcez, Pedro M. 2013. Sociolinguística Interacional, 
21-44. 2a ed. São Paulo. Loyola.

Ribeiro, Branca Telles; Garcez, Pedro M. 2013. Sociolinguística Interacional. 2a ed. São Paulo. Loyola.

Scherre, Maria Marta Pereira. 1994. Aspectos da concordância de número no Português do Brasil. Revista Internacional de Língua Portuguesa (RILP) - Norma e Variação do Português, 37-49. Associação das Universidades de Língua Portuguesa. 12

Tannen, Deborah; Wallat, Cynthia. 1987. "Enquadres interativos e esquemas de conhecimento em interação: Exemplos de um exame/consulta médica”. In: Ribeiro, Branca Telles; Garcez, Pedro M. 2013. Sociolinguística Interacional, 183-214. 2a ed. São Paulo. Loyola.

Tarallo, Fernando. 1990. A pesquisa sociolinguística. Ática S.A. $3^{a}$ edição. São Paulo.

Weinstein, Barbara. 1993. A borracha na Amazônia: expansão e decadência 1850-1920. Tradução de Lólio Lourenço de Oliveira. São Paulo: Hucitec/ EDUSP. 